\title{
Short communication \\ Is breast cancer advocacy distorting the cancer budget to the disadvantage of other tumours?
}

Jim Cassidy

Beatson Oncology Unit, Department of Medical Oncology, University of Glasgow, Switchback Road, Glasgow, G61 1BD, UK

Corresponding author: Jim Cassidy, j.cassidy@beatson.gla.ac.uk

Published: 20 December 2007

This article is online at http://breast-cancer-research.com/content/9/S2/S6 (c) 2007 BioMed Central Ltd

Cancer is a common disease in all Western nations. Current estimates are that about one in three will develop cancer and about one in four will die from the disease. The ageing population means that this problem is likely to become even more prevalent. In contrast, it is hoped that the impact of screening and early detection of disease is that we will see more cancers at an earlier and hence more curable stage in their evolution.

I think it is fair to say that cancer has (or will) touch all of us in a direct way. Hence, we all have close friends or family members who have the disease. Therapy for cancer is unfortunately often palliative because of late presentation and our lack of curative options for most metastatic common solid cancers, so there is much emotion surrounding cancer; some would suggest that this is out of proportion to the prevalence of the disease. Cardiovascular disease kills more people, but it is somehow less emotive to the general public. People who have a myocardial infarction do not ask 'How long have I got doc?', but cancer patients very often do ask for this kind of information.

The most common cancers that we encounter are breast, lung, colorectal and urological. It is clear that the demographics of each of these diseases are distinct. Certain cancers have a predilection for age, sex and social class. Breast cancer is a disease predominantly of middle class females. It is actually commoner with increasing age, but middle-aged women still suffer a high proportion of the burden. Lung cancer almost exclusively occurs in smokers, and it has a higher incidence in lower social classes. Colorectal cancer is slightly more common in well educated people with sedentary occupations. Urological cancer (the bulk of which is prostate cancer) affects older males.

Cancer therapy budgets have in the past been (and continue to be) established with little regard for the prevalence of the disease. In fact, the therapy budgets tend to reflect the number and type of options that we have available, and so breast cancer is out in front because we have multiple modalities of
Breast Cancer Research 2007, 9(Suppl 2):S6 (doi:10.1186/bcr1804)

therapy (screening, surgery, radiotherapy, hormones and chemotherapy). This is in stark contrast to lung cancer, in which (until very recently) most patients presented late, had multiple smoking-induced comorbidities and could only be offered palliative care. Perhaps as we develop more and better therapies for other cancers, some of the therapy budget imbalance will iron out. However, some would advocate that in a disease in which the patient's lifestyle is a major causative factor (for instance, smoking and lung cancer), the burden of care should not be borne by the rest of society. I think this is a dangerous argument. How do we know that lifestyle does not influence all cancer incidence? Perhaps we should not treat any of the sufferers, and what about cardiovascular disease?

The other factor that definitely plays a role is the activities of pressure groups or patient advocacy organizations. The demographics of breast cancer as discussed above lend themselves well to formation of groups of well educated, middle class breast cancer survivors. Hence, multiple and highly influential breast cancer groups do exist; they lobby politicians, take government organizations to court and even appeal to the European Court of Human Rights. This makes those with control of budgets sit up and take notice.

In recent years advocacy groups have appeared representing the other common cancers. Survivorship is less common and less long lasting in these diseases. It is hard to form a pressure group if all the sufferers are dead! These advocacy groups are nowhere near as numerous or advanced in their efforts, but perhaps they will also be a catalyst for change in the future.

If we turn our attention to the research budget the same is true. Breast cancer research is very well funded and always has been. This has a number of interlinked and interdependent effects. More money leads to more research, which leads to more researchers, which leads to more advances, which leads to more therapies, which leads to more publicity, which leads to more therapeutic options, which leads to more survivors, which leads to more advocacy 
groups, which leads to more fundraising for research, and so on. It is simple to appreciate how this cycle feeds off itself in a positive loop.

Unfortunately, this loop has a number of missing parts in the other diseases. Breakthroughs in prostate cancer are uncommon. Survival from aggressive disease is very rare and the disease affects elderly men, who are not efficient as advocates. Colorectal cancer sufferers are loath to discuss their disease in public; it somehow still has more stigma attached to it than does breast cancer.

Is this situation morally justifiable? What can we do about this? Should we try to do anything? These are difficult questions, for which I believe there are no real answers. If one develops a cancer, then that cancer is the most important one to you. Therefore, if breast cancer patients can influence the scene in this way, then perhaps we should not be surprised. It is true that breast cancer therapy has moved forward more than the others have over the past 20 years, so it may be that patient advocacy works. Hence, rather than complain about this, we perhaps should all just join in and make the same happen for every cancer.

\section{Acknowledgement}

This article has been published as part of Breast Cancer Research Volume 9 Supplement 2, 2007: Controversies in Breast Cancer. The full contents of the supplement are available online at http://breastcancer-research.com/supplements/9/S2. 